\title{
Analysis of The Impact of Highway Construction Related to Social and Environment
}

\author{
Luo Xiaofeng ${ }^{1 *}$, Liu Siwei ${ }^{1}$, Yuan yue ${ }^{1}$ \\ ${ }^{1}$ Tianjin Research Institute for Water Transport Engineering, Key Laboratory of Environmental Protection in Water transport \\ Engineering, Ministry of Transport, 300456, China
}

\begin{abstract}
According to the development practice of transportation construction in my country and related literature records, the existing domestic and foreign research on the promotion of transportation construction on the social and economic development and the negative impact on the ecological environment is analyzed, and it is provided a valid reference to exploring the ideas of green transportation construction and establishing a green road evaluation index system.
\end{abstract}

\section{Introduction}

The development of our country's transportation has provided an important contribution for the critical period for building a well-off society in an all-round way, especially in rural areas to get rid of poverty and become rich, and to accelerate the Agricultural and rural modernization. In the "construction, management, maintenance, and maintenance" of highways, it is necessary to strengthen the ecological environment protection, and realize the coordination of economic and social benefits and ecological environmental benefits while improving economic and social benefits. By combing the existing domestic and foreign literature, this paper summarizes the direct and indirect driving effect of highway construction on the economy and society, as well as the different problems that different construction stages bring to the ecological environment. Based on the existing research, weigh the benefits and impacts of highway construction, adopt the supervision evaluation index system in the design and construction process, insist on maximizing benefits, realize the sustainable development of economy and environment, explore ideas and seek for green transportation construction The new balance between construction and ecological protection is an important direction for our highway development.

\section{The impact of highways on the economy and society}

Highway is an important infrastructure facility, which can directly solve the problem of "difficult travel" and promote economic development. Its promotion effect is mainly manifested in direct driving effect and indirect driving effect. Among them, the first direct driving effect is to drive the development of related industries, that is, the increase in demand for local raw materials, machinery and other related industries in the process of road construction, and promote the development of a series of related industries such as transportation and manufacturing, thereby driving local economic development; Increase employment opportunities, that is, the construction and post-maintenance of roads need to hire local residents, thereby creating more employment opportunities. The indirect stimulating effect of highway construction on local economic and social development is reflected in accelerating the adjustment of local industrial layout, prompting local industrial layout to change around the development of roads and transportation; improving the investment environment and convenient transportation increase the attractiveness of investment promotion; driving along the route Economic development, such as promoting the development of restaurants along highways and other service industries such as car repairing and car washing; promoting the development of the logistics industry, reducing transportation costs, and improving the economic efficiency of the logistics industry; promoting the development of tourism, promoting rural self-driving tours, farmhouses and other tourism industries Rise; promote the process of urbanization, strengthen urbanrural connections, promote rural openness, accelerate urban-rural integration and development; coordinate regional economic development, promote local economic relations with the outside world, promote inter-regional material exchange, optimize resource allocation, and drive slower development areas, Finally achieve win-win cooperation and common development ${ }^{[1]}$.

\subsection{Research on the impact of highway construction on economy and society}

With the vigorous advancement of transportation construction, domestic research on the economic and social impact of highway construction has gradually increased, especially in the provinces related to the "Belt and Road". Lean et al. ${ }^{[2]}$ analyzed China's logistics and

\footnotetext{
* Corresponding author: boyluoxfstudent@sina.com
} 
economic data, using dynamic structural model analysis, and pointed out that economic development has significantly increased the demand for logistics services, thereby promoting the development of logistics; Hu et al. ${ }^{[3]}$ pointed out that infrastructure such as highways The capital investment in construction is an important reason for the increase in GDP; Sun et al. ${ }^{[4]}$ used Xinjiang statistical data from 1985 to 2015 and found that highway mileage, highway passenger transportation, and railway freight have played a significant role in the development of Xinjiang's national economy through the LotkaVolterra model. Important role; Wang Boli and Zhang Xiaolei ${ }^{[5]}$ used the combination of input-output analysis and remote sensing to analyze the contribution of Xinjiang's highway transportation infrastructure construction (hereinafter referred to as Xinjiang Transportation Construction) to economic growth from 1997 to 2008, and pointed out that Xinjiang's transportation construction contributed to the economy. The growth contribution not only satisfies the polarization needs of the central area, but also promotes the economic and social development of the peripheral areas through the horizontal diffusion of the three-level vertical ripple effect mode, so that the people of all ethnic groups in the peripheral areas participate in the reform through direct or indirect participation in transportation construction activities. Li Xingjiang and Zhang Yun ${ }^{[6]}$ used stationarity test, cointegration test, and Granger causality test to conduct empirical analysis based on the data between highway construction and economic growth in Gansu Province from 1980 to 2009. The results show that An important reason that affects Gansu's economic development is the unblocked transportation channels. The long-term elasticity of road construction to economic growth from 1980 to 2009 was 2.3404 , and there was a mutual promotion between road construction and economic growth.

\subsection{Quantitative research on impact}

Many existing studies have tried to quantify the economic and social effects of highways. Intensive research was carried out abroad in the $1990 \mathrm{~s}$, such as Washington et al. ${ }^{[7]}$ through literature review and investigation of actual intercity highways and local economic development data, providing economic development potential to Texas highway and public transportation departments The evaluation report and suggested that certain types and specific uses of highways should be promoted to improve the state's competitive advantage. But the results also pointed out that the exact impact of improved traffic on the economy is more difficult to assess. Rephann \& Isserman ${ }^{[8]}$ used the quasi-experimental matching method to investigate the effectiveness of highway investment as an economic development tool. The results show that the most obvious effect of highways on economic growth is in neighboring large cities or interstate counties with a certain degree of urbanization, and it also has a positive impact on promoting the rural economy. The article also pointed out that it is difficult to quantify the economic and social impact of highways because of the grid nature of highways. As a public infrastructure product, it can affect market areas and channels, making it impossible to pass a single location model (von Böventer, 1975 ${ }^{[9]}$ ) for quantification. Therefore, long-term, multi-point economic and social data must be used to improve the robustness of the model. Ireland, which has been vigorously developing transportation in recent years, issued a report "Investing in the Future of Transportation: A Strategic Framework for Land Transport Investment" in 2012. Based on 62 domestic case studies, it was pointed out that for every $1 \%$ change in transportation capital, the rate of return on output was about $0.06 \%$. The report provides a basis for Ireland to continue its transportation construction. At present, Ireland has $21.5 \mathrm{~km}$ of roads per 1,000 residents, which exceeds the EU average of $13.3 \mathrm{~km}$, but the speed of road construction has not slowed down.

\section{The impact of highways on the ecological environment}

The impact of highways on the ecological environment can be divided into the impact on the environment, vegetation, and animals. Specifically, road construction and excavation lead to soil exposed and erosion caused by changes in ground runoff conditions; road engineering destroys surface vegetation, resulting in a decrease in plant species and ecosystem structure and function; road construction destroys wildlife habitat, Changes such as increased roadbeds have led to disturbances in wildlife migration and other activities; road construction will produce chemical pollutants, noise and other impacts. The impact of different highway projects is also different. For example, the roadbed engineering mainly produces linear cutting, including the vegetation and soil changes caused by roadbed excavation or landfill, blocking animal migration, and changing the direction of surface runoff; construction roads also produce linear cutting At the same time, dust may be formed on the road surface; the soil taking and spoiling yard is mainly spread in spots, and the surface vegetation and soil structure are destroyed due to the soil taking or spoiling on the surface, which leads to the patching of the landscape; the sand and gravel yard is causing At the same time of patching, it may also produce surface collapse, change the state of the river bed, and reduce the flood discharge capacity of the river; bridge and culvert projects may change the topography of the river, hydrological conditions and surface vegetation, affect the structure and function of the ecosystem, and aggravate soil erosion to a certain extent, Affect river water quality and other ecological issues; tunnel excavation or disposal of waste residues in tunnel projects can change or destroy natural landscapes, landforms and surface vegetation, reduce regional vegetation coverage and plant diversity, and affect the structure and function of ecosystems, to a certain extent Exacerbate ecological problems such as soil erosion ${ }^{[10]}$.

\subsection{Current status of foreign research}

In order to deeply analyse the impact of highways on the ecological environment, many foreign scholars have 
carried out extensive research. Forman et al. ${ }^{[11]}$ pointed out that from the perspective of landscape, roads have significant impacts on built-up land, forest land, agricultural land and grazing dry land, and discussed specific impact mechanisms. Coffin ${ }^{[12]}$ pointed out that roads will cause changes in land use and land cover, and increase fragmentation and reduce connectivity. Alexander ${ }^{[13]}$ 's research on highways and major ecological impacts is one of the most recognized studies currently. He believes that the highway has become an ecological boundary, which has changed the ecological flow and landscape pattern, and affected the spread of species. Among them, the ecological environment of the United States is approximately $15-20 \%$ affected by road ecology. At the same time, he pointed out that the ecological impacts of highways in different countries and regions are significantly different. Therefore, to explore the impact of highways on the ecological environment must be specific to a specific area, and analysis based on detailed data.

\subsection{Current status of domestic research}

Domestic research involves both qualitative and quantitative aspects, such as Huang Jinhui and Li Qun ${ }^{[14]}$, Sun Qiaobao and Zhen Xiaoyun ${ }^{[15]}$, Chen Aixia, etc. ${ }^{[16]}$, Qian Yibing, etc. ${ }^{[17]}$ described the impact of road construction in different regions from different perspectives. The impact of ecological environment, Zhang Huajun $^{[18]}$, Wei Yajun ${ }^{[19]}$, Zhang Weidong ${ }^{[20]}$, Fang Jianhong, and Li Huanqing ${ }^{[21]}$ all discussed the ecological environmental impacts and measures of Qinghai highway construction, but lacked data support. At present, most domestic quantitative researches are related to the environmental impact assessment of highway construction projects. Since the Ministry of Communications promulgated the "Administrative Measures for Environmental Protection of Transportation Construction Projects (Trial)" in 1987, the environmental impact assessment of highway construction projects has officially started. In the 1990s, environmental assessment methods such as environmental system model method, environmental economic analysis method, and system analysis method were successively proposed, and risk assessment, uncertainty analysis and public health risk assessment content were gradually increased, such as Liu Shan and Yuan Chunxue ${ }^{[22]}$ Carried out a comprehensive evaluation method for the ecological environment impact of highway construction projects, but the weights of the ecological factors such as soil, crops, and air quality adopt the expert scoring method, and the uncertainty is high. In the field of highway transportation environment, Dong Xiaolin's "Social Environmental Impact Assessment of Highway Construction Projects", Zhao Jianqiang's "Highway Construction and Environmental Protection" and Zhang Yufen's "Highway Transportation Environmental Engineering" all involve the impact of highways on the ecological environment ${ }^{[23]}$. In addition, Zheng Xinqi and Wang Aiping [24] carried out comprehensive assessment of regional ecological environment quality based on GIS, Li Xiugang et al. ${ }^{[25]}$ and others developed a GIS graphic overlay method for comprehensive assessment of road environmental impact. Li Tiezhu ${ }^{[26]}$ combined the MOBILE5 model and its Analysis software is used in the process of urban vehicle emission factors and environmental impact assessment. Zeng Sheng and Zheng Jiahui ${ }^{[27]}$ carried out research on fuzzy comprehensive evaluation methods, but the overall performance of these studies is that the evaluation factors are mostly type variables, and the evaluation indicators are limited to data. The amount is lacking, which affects credibility. At present, there is no research to explore the impact of highways and ecological environment based on detailed data, and there is a lack of post-evaluation studies for long-term tracking of highway construction.

\section{4 summary}

To sum up, highways have a huge driving effect on the economy and society, and they also have important impacts on the ecological environment from different aspects. It can be seen from the literature that the current domestic and foreign studies are relatively weak in quantification, mainly due to the lack of detailed data support. Therefore, it is necessary to systematically assess the impact of roads on the economic, social and ecological environment by accumulating raw data and carrying out scientific analysis, and it is also the basis for realizing road planning involving sensitive protection areas.

\section{Acknowledgments}

This work was supported by the central level, scientific research institutes for basic $R \& D$ special foundation (Grants Nos. KJFZJJ190204).

\section{References}

1. Liu Bl, Wu P, Liu Yh. (2010) Transportation Infrastructure and China's Total Factor Productivity Growth: A Spatial Panel Econometric Analysis Based on Provincial Data. Chinese Industrial Economy, 2010(03):54-64.

2. Lean HH, Huang W, Hong J. (2014) Logistics and economic development: Experience from China. Transport Policy:32.

3. Hu K, Gan X-q, Gao K. (2012) Co-integration Model of Logistics Infrastructure Investment and Regional Economic Growth in Central China. Physics Procedia:33-35.

4. Sun Jx, Li Zn, Lei Jq, Teng Dx, Li Sy. (2018) Study on the Relationship between Land Transport and Economic Growth in Xinjiang. Jingxin Sun;Zhinong Li;Jiaqiang Lei;Dexiong Teng;Shengyu Li, 10(1): 117.

5. Wang Bl, Zhang Xl,. (2010) The Contribution of Highway Traffic Infrastructure Construction to Economic Growth in Xinjiang Based on I-O and ESDA. Acta Geographica Sinica, 65(12): 1522-1533. 
6. Li Xj, Zhang Y. (2012) An Empirical Study on Road Infrastruction Construction and Economic Growth of Gansu Province. Science Economy Society, 30: 5-8.

7. J. WE, N. P. Stokes R W. State highway investment and economic development: state-of-the-art review. Econometric models: 1990.

8. Terance R, Andrew I. (1994) New highways as economic development tools: An evaluation using quasi-experimental matching methods. Regional Science and Urban Economics,24(6):105-110.

9. Von Böventer E. (1975) Regional Growth Theory. Urban Studies, 12(1):1-29.

10. Xv Ah. (2009) Brief Discussion on the Impact of Highway Construction on the Ecological Environment of the Three River Source Area. Qinghai Technology, 16(01):50-52.

11. Forman R, Sperling D, Bissonette J, Clevenger A. (2003) Road Ecology: Science And Solutions. Bibliovault OAI Repository, the University of Chicago Press. 2003:201-208.

12. Coffin AW. (2007) From roadkill to road ecology: A review of the ecological effects of roads. J Transp Geogr, 15(5):396-406.

13. Forman, Richard, T., T., Alexander, Lauren, et al. (1998) ROADS AND THEIR MAJOR ECOLOGICAL EFFECTS. Annual Review of Ecology \& Systematics, 163: 51-59.

14. Huang Jh, Li Q, Liu Xl. (2002) Environmental impact of Zhoukou- Provincial Boundary Super highway in Henan Province. Chinese Journal of Ecology, 21(1): 74-79.

15. Sun Qb, Zhen Xy. (2002) The impact of highway construction on the ecological environment and its restoration. Journal of Kunming University of Science and Technology, 02: 68-71.

16. Chen Ax, Ji Dx, Deng Sx. (1999) Design principles and requirements of ecological environment protection in highway construction. Journal of Xi'an Highway University, S1: 3-5.

17. Qian Yb, Lei Jq, Xu Xw. (2001) The adverse effects of the construction of the Tuwu-Dalian Highway on the ecological environment and countermeasures. Arid Land Geography, 02:165-71.

18. Zhang Hj. (2015) Discussion on the ecological environmental impacts and countermeasures of highway construction in Qinghai Province. In: 2015 Annual Conference of the Chinese Society for Environmental Sciences. Shenzhen, Guangdong, China.25-32.

19. Wei Yj. (2010) On the sustainable development of Qinghai highway construction from the perspective of environmental vulnerability. Qinghai Transportation Science and Technology, 04:6-7.

20. Zhang Wd. (2007) The impact of Qinghai expressway construction on the ecological environment and treatment measures. Qinghai Transportation Science and Technology,06: 6-7.
21. Fang Jh, Li Hq. (1997) Discussion on highway construction and environmental protection in Qinghai Province. Qinghai Environment, 1997(02):83-86.

22. Liu S, Yuan Cx. (1999) Research on Comprehensive Evaluation Method of Ecological Environment Impact of Highway Construction Project. Shaanxi Environment,04:3-5.

23. Liu Yn. (2009) Research on the post-evaluation index system and quantitative model of highway ecological environment impact. Changsha University of Science and Technology.

24. Zheng Xq, Wang Ap. (2000) Research on Comprehensive Evaluation of Regional Ecological Environment Quality Based on RS and GISTaking Shandong Province as an Example. Journal of Environmental Sciences, 04:489-493.

25. Li Xg, Wang W, Li F, Deng Xj. (2001) GIS-based graphic overlay method for comprehensive assessment of road environmental impact. Acta Scientiae Circumstantiae, 04:448-453.

26. Li Tz. (2001) Research on Urban Traffic Atmospheric Environmental Impact Assessment and Prediction Technology [PhD]: Southeast University.

27. Zeng S, Zheng (2011) Jh. Multi-level fuzzy extension evaluation analysis of expressway landscape in lake area. Journal of Changsha University of Science and Technology (Natural Science Edition),8(01):7-13. 